\title{
Profiling of Extracellular Small RNAs Highlights a Strong Bias towards Non-Vesicular Secretion
}

\author{
Helena Sork ${ }^{1,2, *}$, Mariana Conceicao ${ }^{3}$, Giulia Corso ${ }^{1}$, Joel Nordin ${ }^{1,4}$, Yi Xin Fiona Lee ${ }^{3,+}{ }^{+}$, Kaarel Krjutskov ${ }^{5}$, \\ Jakub Orzechowski Westholm ${ }^{6}\left({ }^{\circ}\right.$, Pieter Vader ${ }^{7,8}$, Marie Pauwels ${ }^{9,10}$, Roosmarijn E. Vandenbroucke ${ }^{9,10}{ }^{(}$, \\ Matthew JA Wood ${ }^{3,11}$, Samir EL Andaloussi ${ }^{1, \ddagger}$ and Imre Mäger $2,3, *, \ddagger$
}

1 Department of Laboratory Medicine, Karolinska Institutet, SE-141 52 Huddinge , Sweden; giulia.corso@ki.se (G.C.); joel.nordin@ki.se (J.N.); samir.el-andaloussi@ki.se (S.E.A.)

2 Institute of Technology, University of Tartu, 50411 Tartu, Estonia

3 Department of Paediatrics, University of Oxford, Oxford OX3 9DU, UK;

mariana.conceicao@paediatrics.ox.ac.uk (M.C.); leeyxf@gis.a-star.edu.sg (Y.X.F.L.); matthew.wood@paediatrics.ox.ac.uk (M.J.W.)

4 Evox Therapeutics, King Charles House, Oxford OX1 1JD, UK

5 Competence Centre on Health Technologies, 50411 Tartu, Estonia; kaarel.krjutshkov@ccht.ee

6 Science for Life Laboratory, Department of Biochemistry and Biophysics, National Bioinformatics Infrastructure Sweden, Stockholm University, Solna, Box 1031, SE-171 21 Stockholm, Sweden; jakub.westholm@scilifelab.se

7 Department of Clinical Chemistry and Haematology, University Medical Center Utrecht, 3584 CX Utrecht, The Netherlands; pvader2@umcutrecht.nl

check for updates

Citation: Sork, H.; Conceicao, M.; Corso, G.; Nordin, J.; Lee, Y.X.F.;

Krjutskov, K.; Orzechowski Westholm, J.; Vader, P.; Pauwels, M.; Vandenbroucke, R.E.; et al. Profiling of Extracellular Small RNAs Highlights a Strong Bias towards Non-Vesicular Secretion. Cells 2021, 10, 1543. https://doi.org/10.3390/ cells10061543

Academic Editor: Alice Conigliaro

Received: 12 May 2021

Accepted: 14 June 2021

Published: 18 June 2021

Publisher's Note: MDPI stays neutral with regard to jurisdictional claims in published maps and institutional affiliations.

Copyright: (c) 2021 by the authors. Licensee MDPI, Basel, Switzerland. This article is an open access article distributed under the terms and conditions of the Creative Commons Attribution (CC BY) license (https:/ / creativecommons.org/licenses/by/ $4.0 /)$.
8 Department of Experimental Cardiology, University Medical Center Utrecht, 3584 CX Utrecht, The Netherlands

9 Barriers in Inflammation Lab, VIB Center for Inflammation Research, VIB, 9052 Ghent, Belgium; marie.pauwels@irc.vib-ugent.be (M.P.); roosmarijn.vandenbroucke@irc.vib-ugent.be (R.E.V.)

10 Department of Biomedical Molecular Biology, Ghent University, 9052 Ghent, Belgium

11 MDUK Oxford Neuromuscular Centre, Oxford OX1 3QX, UK

* Correspondence: helena.sork@ki.se (H.S.); imre.mager@paediatrics.ox.ac.uk (I.M.); Tel.: +46-858-583-657 (H.S.); +1-865-272-199 (I.M.); Fax: +46-8585-838-00 (H.S.); +1-865-272-420 (I.M.)

+ Current address: Genome Institute of Singapore, Singapore 138672, Singapore.

$\ddagger$ Shared authorship.

Abstract: The extracellular environment consists of a plethora of molecules, including extracellular miRNA that can be secreted in association with extracellular vesicles (EVs) or soluble protein complexes (non-EVs). Yet, interest in therapeutic short RNA carriers lies mainly in EVs, the vehicles conveying the great majority of the biological activity. Here, by overexpressing miRNA and shRNA sequences in parent cells and using size exclusion liquid chromatography (SEC) to separate the secretome into EV and non-EV fractions, we saw that $>98 \%$ of overexpressed miRNA was secreted within the non-EV fraction. Furthermore, small RNA sequencing studies of native miRNA transcripts revealed that although the abundance of miRNAs in EVs, non-EVs and parent cells correlated well $\left(\mathrm{R}^{2}=0.69-0.87\right)$, quantitatively an outstanding $96.2-99.9 \%$ of total miRNA was secreted in the non-EV fraction. Nevertheless, though EVs contained only a fraction of secreted miRNAs, these molecules were stable at $37^{\circ} \mathrm{C}$ in a serum-containing environment, indicating that if sufficient miRNA loading is achieved, EVs can remain delivery-competent for a prolonged period of time. This study suggests that the passive endogenous EV loading strategy might be a relatively wasteful way of loading miRNA to EVs, and active miRNA loading approaches are needed for developing advanced EV miRNA therapies in the future.

Keywords: extracellular vesicles; small RNA; SEC; extracellular RNA; miRNA

\section{Introduction}

The constant drive to find novel carriers of RNA therapeutics has witnessed a shift from artificial delivery systems to nature-inspired biomolecule carriers, such as extracellular 
vesicles (EVs). Owing to their pivotal role in cell-to-cell communication as well as the inherent ability to deliver bioactive lipids, proteins and nucleic acid, EVs hold a spotlight position in the research of advanced therapeutic carriers.

EVs contain a wide range of nucleic acid molecules, and though stretches of up to several kilobases in size have been detected [1], the majority of the encapsulated material does not exceed 200 nucleotides [2,3]. Therefore, most studies focus on loading EVs with therapeutic miRNAs and other short miRNA-like RNAs, such as siRNAs and shRNAs [4-8]. In order to load EVs with RNA, exogenous loading as well as endogenous overexpression of therapeutic genes has been utilized, the latter often being preferred [9-11]. Nevertheless, despite significant effort, the enrichment of EVs with the nucleic acid of interest still remains challenging.

It is evident from previous studies that most of the extracellular nucleic acids are not associated with vesicular structures, being either bound to protein complexes or lipoprotein particles [12-16]. Yet, as biological effects of EV-depleted specimens are minimal [17-19], it is generally accepted that practically all the biological activity is rather conveyed by EVs than other circulating nucleic acid carriers. Early studies on nucleic acid transfer via EVs were published more than a decade ago [20-22]. These have now been complemented with numerous reports describing the transfer of EV-RNA, which, for example, modulates metabolic- [23,24] and immune responses [25], combats cancer [4,6,7,26,27], ameliorates liver diseases [28,29] and even acts across the blood-brain barrier [5,8].

The presence of a distinct miRNA per EV has been estimated to be approximately 1 in 100, or even 1 in 10,000 [30-32], being largely insufficient to ensure solid therapeutic delivery [33]. This underscores the urgency to understand miRNA (and more broadly short RNA) accumulation in EVs and non-EVs and could provide important background information on which strategies to explore for enriching the desired short RNAs to EVs. Different loading strategies have already been employed [10], but frequently without considering the context of global miRNA secretion.

Here, we analyze the relative abundance of a selection of miRNA molecules in the EV and non-EV secretory fractions at their basal level as well as after endogenous overexpression. These results are viewed in the global context of basal miRNA secretion to provide extended knowledge on extracellular sorting of short RNA sequences.

\section{Materials and Methods}

\section{1. miRNA Overexpression}

To express precursors for the specific miRNAs, pri-miRNA sequences were amplified by PCR using Phusion ${ }^{\circledR}$ High-Fidelity DNA Polymerase (NEB BioLabs, Ipswich, MA USA) from the genomic DNA of human embryonic kidney (HEK293T) cells with the oligonucleotide primers (Integrated DNA Technologies, Coralville, IA, USA) described by Diederichs et al. [34]. The obtained pri-miRNA sequences were cloned into the pEGFP-N1 backbone vector by using AgeI and $\mathrm{XbaI}$ restriction enzymes and T4 DNA ligase (NEB BioLabs, Ipswich, MA, USA). For shRNA overexpression, luciferase-targeting shRNA oligonucleotides (Integrated DNA Technologies, Leuven, Belgium) were cloned into the shRNA expression plasmid downstream of the U6 promoter, using the BbsI restriction enzyme [35]. The shRNA oligonucleotide sequences were: CCGGAAGAGCACTCTCATCGACAAGCTCGAGCTTGTCGATGAGAGTGCTCTTTTTTTG, and AATTCAAAAAAAGAGCACTCTCATCGACAAGCTCGAGCTTGTCGATGAGAGTGCTCTT. Subcloning Efficiency ${ }^{\mathrm{TM}} \mathrm{DH} 5 \alpha^{\mathrm{TM}}$ Competent Cells (Life Technologies Invitrogen, Carlsbad, CA, USA) were used to propagate the plasmid, followed by plasmid purification using a QIAprep Spin Miniprep Kit (Qiagen, Hilden, Germany) and sequencing (Source BioScience LifeSciences, Oxford, UK). For overexpression studies, HEK293T cells were maintained in high-glucose (4.5 g/L) DMEM GlutaMax (Thermo Fisher Scientific, Waltham, MA, USA) supplemented with $10 \%$ fetal bovine serum (FBS, Thermo Fisher Scientific, Waltham, MA, USA) and transfected (at $~ 80-90 \%$ confluency) with pri-miRNA expression vectors by using polyethyleneimine (PEI, Cat.No. 408727, Sigma-Aldrich, St. Louis, MO, USA) transfection 
at a DNA:PEI ratio of 1:4 (25 $\mathrm{g}$ ger $15 \mathrm{~cm}$ cell culture dish). After $4 \mathrm{~h}$ of post-transfection, the cells were washed once with phosphate-buffered saline (PBS) solution (Thermo Fisher Scientific, Waltham, MA, USA), followed by media changed to OptiMEM Reduced serum medium (Thermo Fisher Scientific, Waltham, MA, USA). After $48 \mathrm{~h}$ postconditioning, the EVs were isolated as described below.

\subsection{EV Isolation for Overexpression and Validation}

For miRNA overexpression studies, after $48 \mathrm{~h}$ of media conditioning, the EVs were isolated by using the Amicon Ultra-15 100 kDa molecular weight cut-off spin-filters (Millipore, Darmstadt, Germany), discriminating the retentate and flow-through/filtrate. Otherwise, the retentate was subjected to ultrafiltration SEC fractionation using the S-400 as described in [36] (fractionation of overexpressed miRNA secretome) or fractionated by Tricorn 10/300 columns (Sigma-Aldrich, Saint-Louis, MO, USA) packed in-house with Sepharose Fast Flow 4 resin (GE Healthcare, Pittsburgh, PA, USA) (miRNA validation). In the case of miRNA overexpression, the A280 and RNA quantification measurements (Quant-iT RiboGreenRNA Assay Kit; Thermo Fisher Scientific, Waltham, MA, USA) across the elution profile were used to set the location of fractions 1 to 5 (each spanning $10 \mathrm{~mL}$ ) in a way that the cross-talk between the set ranges would be minimal, yet would cover the major changes in the protein and RNA profiles. For miRNA validation, the 'non-EV' fraction contained the non-vesicular fractions from the SEC as well as the flow-through from the $100 \mathrm{kDa}$ ultrafiltration step.

\section{3. miRNA Quantification by qRT-PCR}

For miRNA quantification, an appropriate amount of Trizol LS (Thermo Fisher Scientific, Waltham, MA, USA) was used to prepare the samples for subsequent RNA extraction according to the manufacturer's protocol. For miRNA validations, to account for the variation in RNA extraction efficiencies, $3 \mu \mathrm{L}$ of a $5 \mu \mathrm{M}$ synthetic miRNA oligonucleotide, cel-miR-39 (5'-UCACCGGGUGUAAAUCAGCUUG) (Integrated DNA Technologies, Leuven, Belgium), was added to each sample at the phenol extraction stage. In all cases, cDNA synthesis was performed by using the TaqMan MicroRNA Reverse Transcription Kit and the respective hairpin primers from TaqMan MicroRNA Assays (let-7a-5p assay ID:000377 and let-7b-5p assay ID:000378, miR-186-5p assay ID:002285; miR-210-3p assay ID: 000512; miR-16-5p assay ID:000391; miR-21-5p assay ID:000397 and miR-100-5p assay ID:000437; all from Thermo Fisher Scientific, Waltham, MA, USA). The quantification was performed by using the TaqMan Gene Expression Master Mix together with the respective TaqMan MicroRNA Assays on a Step-One Real-Time PCR instrument (Thermo Fisher Scientific, Waltham, MA, USA). shRNA detection was performed by synthesizing cDNA as above, but using custom-designed hairpin RT primers and amplified using KiCqStart SYBR Green qPCR Ready Mix (Sigma Aldrich, Saint-Louis, MO, USA) on a Step-One Real-Time PCR instrument, as above. The PCR efficiency of each reaction was calculated with the LinRegPCR program (developed by Dr. Jan Ruijter, Heart Failure Research Center, The Netherlands), while the Ct values were obtained from StepOne Software (Applied Biosystems, Waltham, MA, USA). In the case of overexpression studies, an equal amount of input RNA was used for reverse transcription. For miRNA validations, the total miRNA quantity was normalized to cel-miR-39 levels and further corrected for the volume of the respective fractions (Sepharose Fast Flow 4 fractionation volumes of 3-3.5 mL for EVs and 131-133 mL for non-EV (non-EV fraction + flow-through of $100 \mathrm{kDa}$ ultrafiltration units)). For EV miRNA stability studies, EVs were isolated and purified as above, mixed with FBS at a final serum concentration of $10 \%$ and incubated at $37{ }^{\circ} \mathrm{C}$ for indicated times. At the end of each time point, Trizol LS was added to samples, and the RNA was extracted and analyzed by qPCR, as above. 


\subsection{EV Isolation for Small RNA Sequencing}

Neuro2a, hTERT-MSCs and HEK293T cell-lines were maintained in high-glucose (4.5 g/L) DMEM GlutaMax (Thermo Fisher Scientific, Waltham, MA, USA; HEK293T) or RPMI medium 1640 (Thermo Fisher Scientific, Waltham, MA, USA; hTERT-MSCs) supplemented with $10 \%$ fetal bovine serum (FBS, Thermo Fisher Scientific, Waltham, MA, USA). All cells were cultured in a humidified atmosphere at $37{ }^{\circ} \mathrm{C}$ and $5 \% \mathrm{CO}_{2}$. A total of $6 \times 10^{6}$ cells were first seeded onto $15 \mathrm{~cm}$ cell culture dishes. After $24 \mathrm{~h}$, cells were washed with $0.01 \mathrm{M}$ phosphate-buffered saline (PBS) to ensure removal of any residual FBS before a media change to OptiMEM (Thermo Fisher Scientific, Waltham, MA, USA) supplemented with 1\% Antibiotic Antimycotic Solution (Sigma-Aldrich, Saint-Louis, MO, USA). The supernatant was collected after $48 \mathrm{~h}$, and EVs were harvested by ultrafiltration SEC fractionation as described in [36]. To obtain the non-vesicular pool, flow-through from the $100 \mathrm{kDa}$ ultrafiltration step was combined with the non-vesicular fractions from the SEC fractionation and thereafter concentrated on the $10 \mathrm{kDa}$ molecular weight cut-off (MWCO) Amicon spin filters (Merck Millipore, Burlington, MA, USA), the latter of which was also used to concentrate the vesicular fractions. In some control experiments, when specifically indicated, $100 \mathrm{kDa}$ MWCO spin filters were used instead. Immediately after concentrating, all samples were mixed with Trizol LS (Thermo Fisher Scientific, Waltham, MA, USA) and stored at $-80^{\circ} \mathrm{C}$ until RNA extraction for small RNA sequencing analysis. The abovementioned workflow was used to generate three biological replicates from each cell line.

\subsection{EV Characterization}

Nanoparticle tracking analysis (NTA) was performed by using the NanoSight NS500 nanoparticle analyzer (Malvern Instruments, Malvern, UK) to measure the size distribution and concentration of the purified EVs. The EV samples were diluted in PBS, and the movement of the particles was recorded within five $30 \mathrm{~s}$ videos that were subsequently analyzed using the NTA Software 2.3 (Malvern Instruments, Malvern, UK) at detection threshold 5, camera gain 350 and shutter setting 800. Transmission Electron Microscopy (TEM) was performed as described in [37].

\subsection{Western Blot}

Sample protein concentrations were measured using the Pierce ${ }^{\mathrm{TM}}$ BCA Protein Assay Kit (Thermo Fisher Scientific, Waltham, MA, USA), and an equal amount of protein $(10 \mu \mathrm{g})$ of each sample was separated by SDS-PAGE by using NuPAGE Sample Reducing Agent (Thermo Fisher Scientific, Waltham, MA, USA) on precast NuPAGE 4-12\% BisTris Protein Gels (Thermo Fisher Scientific, Waltham, MA, USA). Thereafter the proteins were transferred to a polyvinylidene difluoride (PVDF) membrane and probed using antiCalnexin (ab22595, Abcam, Cambridge, UK), anti-Alix (ab117600, Abcam, Cambridge, UK) or Syntenin-1 (TA504796, OriGene, Rockville, MD, USA) antibodies as per manufacturer's instructions. The secondary antibodies used were goat anti-mouse IRDye $800 \mathrm{CW}$ (926-32210, LI-COR Biosciences, Lincoln, NE, USA) or donkey anti-rabbit IRDye $800 \mathrm{CW}$ (926-32213, LI-COR Biosciences, Lincoln, NE, USA). Precision Plus Protein Dual Color Standards ladder was utilized to determine the size of protein bands (Bio-Rad Laboratories, Hercules, CA, USA). The final blots were imaged using the LI-COR Odyssey CLx infrared imaging system (LI-COR Biosciences, Lincoln, NE, USA).

\subsection{Small RNA Sequencing and Data Analysis}

Library preparation (from $60 \mathrm{ng} \pm 10 \%$ of total RNA),small RNA sequencing and data analysis regarding mapping and annotation were performed as outlined in [38]. For data visualization (principal component analysis, correlation scatterplots, heatmaps), raw read counts were transformed in R-studio software ( $R$ version 3.4.2) [39] by using the approach of variance stabilizing transformation (vsd; blinded $=\mathrm{F}$ ). Differential expression analyses of miRNAs were performed by using the R package DESeq2 [40], including mature miRNAs 
exceeding a raw read count cut-off across the studied samples (RowMeans $>1$ within the studied cell line). Heatmaps of differentially expressed miRNAs (vsd counts, local zero-centered normalization) were generated by using the Multiple Experiment Viewer program (Version 4.9.0) [41]. The miRNAs were hierarchically clustered by using the average linkage clustering method, Pearson distance metric and optimized gene leaf order.

\subsection{Statistical Analysis}

The statistics for RNA stability experiments were performed using simple linear regression analysis using GraphPad Prism Version 6 (GraphPad Software, Inc., La Jolla, CA, USA). The same software (Version 7) was used for statistical fold enrichment analyses with two-way ANOVA, Tukey post-hoc correction. The statistics from the differential expression analysis of miRNAs were generated by the R software package DESeq2 [40].

\section{Results}

It is known that cells constantly release miRNA into the extracellular space. A fraction of secreted miRNA is encapsulated in EVs, yet according to previous reports [12,13], a large amount can be detected outside vesicular structures. To be able to separate the secretome into vesicular (EVs) and non-vesicular fractions (non-EVs), this study has employed sizeexclusion chromatography (SEC) (Figure 1a). We have previously validated SEC workflow for its suitability to separate EVs from the non-vesicular secreted material and found that the total yield of the entire EV isolation workflow was high (>70\%) [36]. Furthermore, the isolated EVs had high purity as EV protein markers were detected only in the SEC eluate, corresponding to the void volume peak (i.e., the EV peak) and not in fractions that eluted later (i.e., the non-EV peak) [36].

In the present study, SEC-purified EVs were characterized by Western blot, Nanoparticle Tracking Analysis (NTA) and transmission electron microscopy (TEM) (Supplementary Material Figure S1). Further analysis of eluted SEC fractions confirmed that high molecular weight particles, as detected by NTA, eluted all in the void volume peak (Supplementary Material Figure S2A,B). Also, as expected, most of the protein and RNA were found to elute in the non-EV area of the chromatogram, with the latter being susceptible to RNAseA treatment (Supplementary Material Figure S2C,D). Additional control experiments with $100 \mathrm{kDa}$ MWCO ultrafiltration spin filters showed that all detectable particles remained in the retentate while most of the miRNA was found in the filtrate (Supplementary Material Figure S2E,F), corroborating with the RNA elution profile of the SEC chromatogram. Due to the widely recognized concerns on bovine serum-derived miRNA contamination (even when EV-depleted serum is used) [42,43], the conditioned medium was prepared using serum-free Opti-MEM, being suitable for EV production as shown previously [44,45].

\subsection{Pri-miRNA and U6-shRNA Overexpression Leads to RNA Secretion in the Non-EV Fraction}

Many studies focusing on developing EVs as therapeutic RNA carriers aim to enrich miRNA in EVs by overexpressing the respective transcripts in EV-producing cells. Yet, little is known about miRNA secretion patterns when using such a strategy. To investigate to what extent miRNAs of interest get released to the extracellular space, we transiently overexpressed pri-let-7a and pri-let-7b in HEK cells (yielding a 7-10 $\times$ and 5-7× increase in expression level, respectively (data not shown)) and quantified the respective mature miRNA levels in the EV and non-EV portion of the secretome. This analysis revealed that the majority of overexpressed let-7a and let-7b mature transcripts were secreted in the non-EV fraction, whereas the EV fraction contained $<2 \%$ of the respective miRNAs (Figure 1b). This suggests that while miRNA overexpression in source cells does lead to its increased level in EVs, the majority of extracellular transcripts are predominantly found in the non-EV fraction. To clarify, throughout the study, the non-EV secretory fraction was obtained by combining the non-EV fraction from SEC with the $100 \mathrm{kDa}$ ultrafiltration flow-through, allowing us to look at the global non-EV material. 


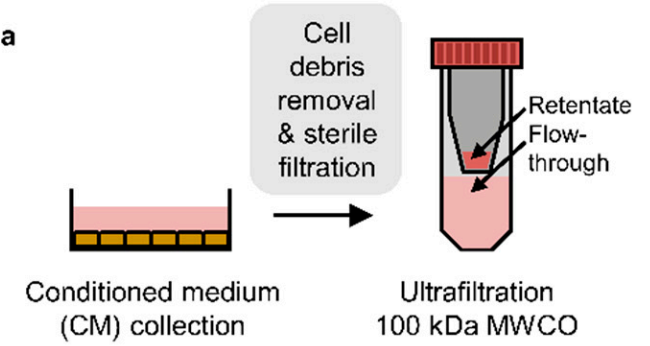
(CM) collection

$$
100 \text { kDa MWCO }
$$

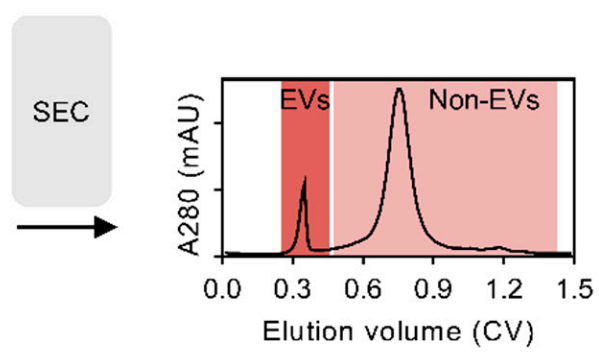

d

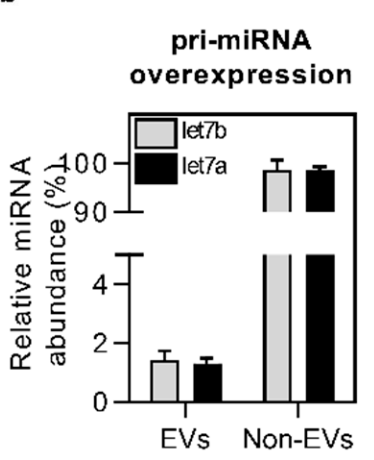

c

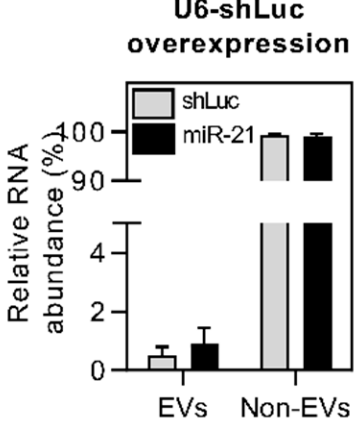

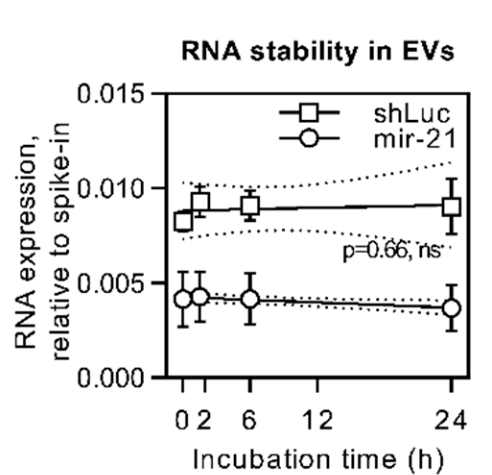

Figure 1. EV isolation workflow and the secretory distribution and stability of overexpressed miRNAs. (a) HEK293T (HEK) cells and hTERT-MSCs (MSCs) were seeded to $15 \mathrm{~cm}$ tissue culture plates. For producing conditioned medium (CM), cells were incubated in Opti-MEM for $48 \mathrm{~h}$. For $\mathrm{CM}$ fractionation, it was first cleared from cell debris and large particles using two centrifugation steps $(5 \mathrm{~min}$ at $300 \times g$ and $10 \mathrm{~min}$ at $1200 \times g)$ followed by $0.22 \mu \mathrm{m}$ sterile filtration. The pre-cleared $\mathrm{CM}$ was concentrated by ultrafiltration on $100 \mathrm{kDa}$ MWCO filters, followed by retentate fractionation into EV and Non-EV fractions using SEC with Sephacryl S-400 resin. Finally, to obtain the global non-EV pool used in the study, the Non-EV pool from SEC was combined with the flow-through from the ultrafiltration step. $(\mathbf{b}, \mathbf{c})$ miRNA sequences were transiently overexpressed in cells using pri-miRNA or U6-shRNA expression plasmids, followed by miRNA quantification using RT-qPCR. Strikingly $>98 \%$ of overexpressed miRNAs were found to be secreted to the non-EV fraction (relative RNA abundance in \% over the total is shown). Nevertheless, despite that only a minor fraction of miRNA was found in EVs, these miRNAs showed high serum stability for up to $24 \mathrm{~h}(p=0.66$, simple linear regression analysis by GraphPad Prism Version 6) (d). $\mathrm{N}=3$ for all experiments.

The pri-miRNA expression vectors used above were driven by the CMV promoter, which is a Pol II promoter and requires full processing of the overexpressed pri-miRNA transcripts by respective miRNA processing machinery (DROSHA, DICER1, etc.). However, in many cases, when aiming to load EVs with small RNA, the transcription is initiated using the U6 (Pol III) promoter. This promoter facilitates highly efficient RNA transcription with well-defined transcription start and termination sites, being extensively used for expressing short hairpin RNA (shRNA) for siRNA-like gene silencing purposes. Having this in mind, we also overexpressed a shRNA transcript (shRNA targeted against Firefly luciferase, shLuc) in HEK cells to measure its effect on shRNA secretion in EVs. Interestingly, even though the U6-promoter-driven shRNA expression level was significantly higher than the miRNA expression level using the CMV-driven pri-miRNA expression vectors (data not shown), we observed that the shRNA secretion profile remained unchanged. Namely, $<2 \%$ of all secreted shLuc was found in the EVs, where similarly to naturally secreted miR-21 transcripts, it remained stable in a serum-containing environment for $24 \mathrm{~h}$ (Figure 1c,d). This indicates that even though only a minority of miRNA is secreted with EVs, it remains 
stable over a long period of time and may thus be biologically active when delivered to recipient cells.

\subsection{Small RNA Secretome Is Predominantly Composed of miRNA and piRNA-Like Sequences}

After observing that the overexpressed miRNAs are predominantly secreted via a non-vesicular route, we were curious to investigate whether the same trend applies to miRNAs at their basal expression level. Hence, we sequenced RNA from cells, SEC-derived EV and non-EV fractions from HEK and MSC cell lines and focused on the analysis of reads between 17 and 35 nucleotides in length. This restriction was applied in order to not only cover full-length miRNAs but also to include other small RNAs (sRNA) and check for the presence of larger RNA fragments. The latter have been found in EVs by the authors and others even when focusing on short reads (Figure 2a) [38,46,47].

a

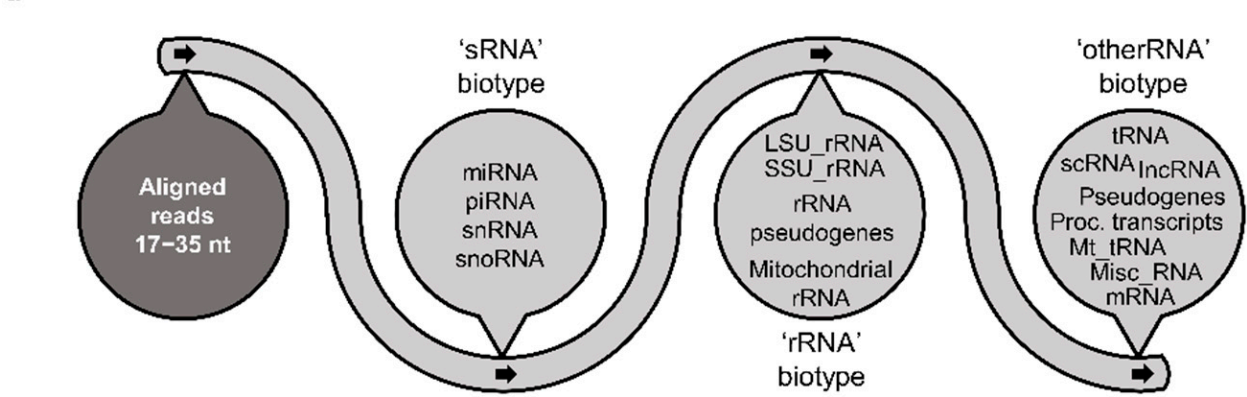

b

HEK

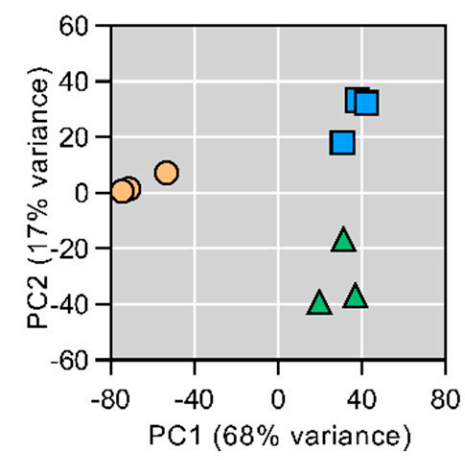

MSC

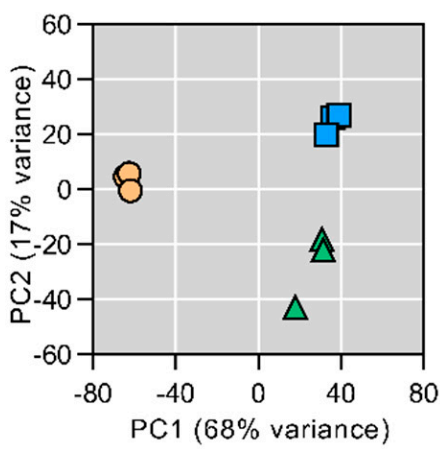

Cells

$\square$ EVs

$\triangle$ Non-EVs

Figure 2. Sequencing workflow and Principal Component Analysis of all uniquely annotated reads. (a) RNA was extracted from EV and Non-EV fractions and subjected to sequencing. RNA sequences with a read length of 17-35 nt were aligned to the human genome and annotated in a stepwise manner first to the 'sRNA' biotype (miRNA, piRNA, snRNA, snoRNA), then to the 'rRNA' biotype (LSU_rRNA, SSU_rRNA, rRNA pseudogenes, mitochondrial rRNA) and finally to the 'otherRNA' biotype (tRNA, scRNA, IncRNA, pseudogenes, processed transcripts, mt_tRNA, misc_RNA, mRNA). (b) Principal Component Analysis of all uniquely annotated reads of both HEK (left panel) and MSC (right panel) samples showed clear cluster separation of the cell, EV and Non-EV samples. Looking at the principal component 1 (PC1, explaining $68 \%$ of variance), the secretory fractions of both samples are more similar to each other than to parent cells.

Principal component analysis (PCA) showed a clear cluster separation between cell, $\mathrm{EV}$ and non-EV samples, indicating significant differences in their RNA composition (Figure 2b). Upon detailed analysis of the sRNA secretome, we found that miRNA and piRNA-like sequences together constituted the majority of sRNA biotype reads (Figure $3 \mathrm{a}, \mathrm{b}$ ) and, depending on the secretory fraction and cell type, covered between $88-98 \%$ of sRNA sequences. When comparing with piRNA and miRNA levels in parent cells, piRNA reads were enriched in both EV and non-EV samples, whereas miRNAs 
were not (Supplementary Material Figure S3A,B). Due to sequence similarities and conflicting data in piRNA databases, the sequences which aligned to piRNA loci were also checked for the presence of piRNA features (such as read length distribution and the presence of $5^{\prime}$ uracil) and potential overlap with tRNA annotations (Supplementary Material Figure S3C-H). The highest level of tRNA-overlapping sequences was found in non-EV samples, yet even when the potentially tRNA-derived sequences were removed from the analysis, the trend of EVs being enriched in piRNA sequences (compared to their parent cells) remained largely unchanged (Supplementary Material Figure S3G,H).

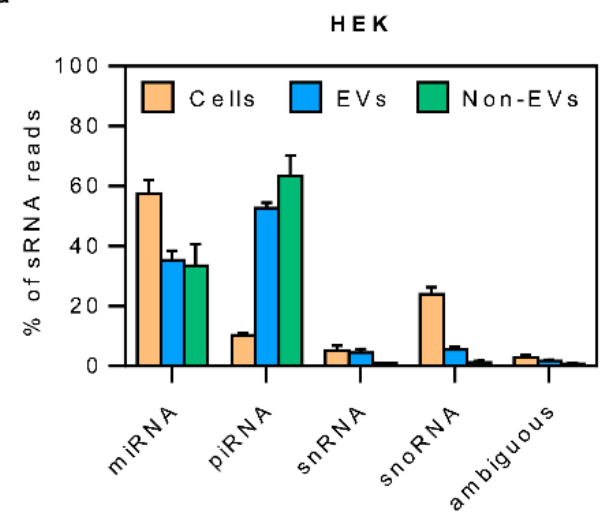

c

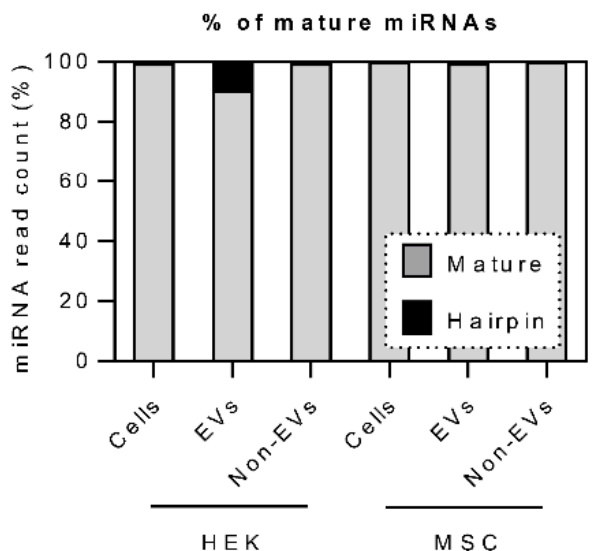

e

\begin{tabular}{cccc|}
\multicolumn{1}{c}{ e } & \multicolumn{3}{c}{$\begin{array}{l}\text { HEK, miRNA expression } \\
\text { correlation coefficients }\end{array}$} \\
\cline { 2 - 4 } Cells & $\mathrm{X}$ & 0.69 & 0.78 \\
EVs & 0.69 & $\mathrm{X}$ & 0.78 \\
Non-EVs & 0.78 & 0.78 & $\mathrm{X}$ \\
\hline
\end{tabular}

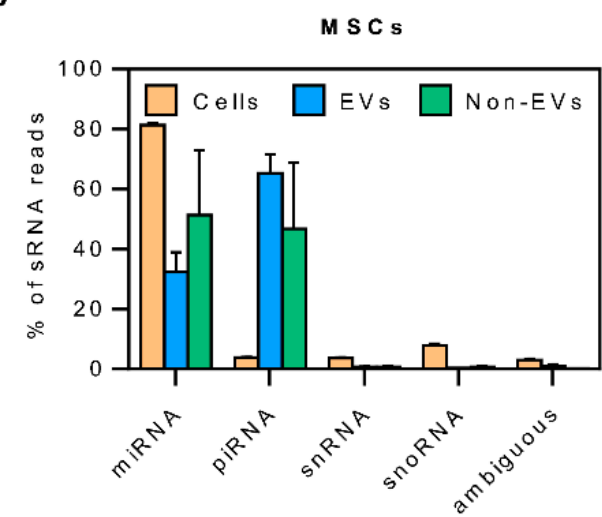

d

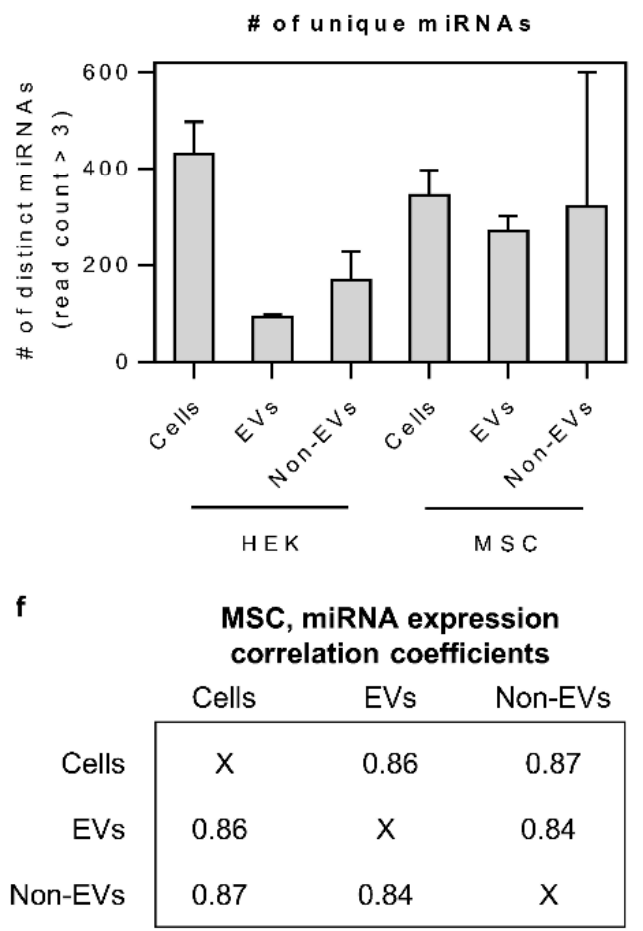

Figure 3. sRNA composition, characteristics and correlation in source cells and secretory fractions. $(\mathbf{a}, \mathbf{b})$ Within the sRNA biotype, both for HEK and MSC samples, most of the reads comprised miRNA and piRNA sequences. While cellular RNA was rich in the miRNA, EV and Non-EV samples were dominated by sequences aligning to piRNA genes. (c,d) The vast majority of detected miRNA sequences were fully processed, and the number of distinct miRNAs was generally higher in cell samples than in EVs, particularly for HEK samples. (e,f) The correlation of miRNA expression between cellular, EV and Non-EV samples was high, ranging from Pearson $\mathrm{R}^{2}=0.69$ to 0.87 . 
Overall, it must be noted that the proportion of sRNA biotype sequences in the RNA secretome was relatively low ( $<20 \%$ of total reads within the $17-35 \mathrm{nt}$ read length range). The majority of the annotated sequences were 'rRNA' and 'otherRNA' fragments (Supplementary Material Figure S4), the latter mainly covering fragments of tRNA and protein-coding sequences (Supplementary Material Figure S5). Secreted miscellaneous RNA in both cell types consisted primarily of Y RNA sequences. Yet, small cytoplasmic RNAs and vault RNAs, which were prominently observed in EVs, remained practically undetected in the non-EV secretome (Supplementary Material Figure S5).

\subsection{The Bulk of Secretory miRNAs Reflect the Content of the Source Cells}

After observing that miRNA and piRNA were the most abundant sRNA species both in EVs and non-EVs, we next decided to analyze whether there are any differences in miRNA secretion between the different fractions. We observed that nearly all miRNA reads fell in the range of 20-24 nucleotides in length and represented mature miRNA sequences (Figure 3c). Interestingly, the number of distinct miRNAs detected in the HEK secretome was lower than in HEK cells, whereas in MSC samples, the miRNA numbers were relatively similar in cells, EVs as well as non-EVs (Figure 3d).

The analysis of expression levels of individual miRNAs revealed a good correlation between the EV and non-EV samples (Pearson $\mathrm{R}^{2}=0.78$ and $\mathrm{R}^{2}=0.84$ for HEK and MSC samples, respectively; Figure $3 \mathrm{e}, \mathrm{f})$. When comparing each of the secretory fractions to cells, miRNA expression in both EVs and non-EV fractions correlated highly to parent MSCs $\left(R^{2}=0.86\right.$ and $R^{2}=0.87$, respectively). The same was seen for the HEK non-EV sample $\left(R^{2}=0.78\right)$, yet miRNAs in HEK EVs showed a somewhat lower correspondence to their source cells $\left(R^{2}=0.69\right)$. Nevertheless, these generally high correlation coefficients indicate that, for most miRNAs, a significant contributor to their secretory level is their expression in the cells, suggesting an average stochastic secretion mechanism with evidence on selective sorting in the case of some miRNAs.

\subsection{Enriched Secretory miRNAs Have Low Expression Levels in Cells}

Even though miRNA expression was highly correlated between cells, EVs and nonEVs, there were several individual miRNA sequences that seemed to be enriched in different fractions of the secretome. To confirm that, we performed differential expression (DE) analysis of mature miRNA levels in both cell types by comparing miRNA expression between EVs and non-EVs as well as against their background level in their source cells. As a general observation, miRNAs that were enriched in EVs and in the non-EV fraction displayed low cellular expression levels (Figure 4a,b). In HEK-derived samples, a total of 460 distinct miRNAs were detected, out of which, as compared to their source cells, 38 and 31 miRNAs were differentially expressed in EV and non-EV samples, respectively (Figure 4a; Supplementary Material Table S1). Out of 516 mature miRNAs that were included in the analysis for MSC-derived samples, we detected 78 and 83 DE miRNAs in EV and non-EV samples, respectively, as compared to source cells ( $\mathrm{p}_{\mathrm{adj}}<0.05, \log 2$ fold change $\geq 1.5$; Figure $4 \mathrm{~b}$; Supplementary Material Table S2). As exemplified by the heatmaps and hierarchical clustering analysis, miRNAs with decreased secretion levels clustered together for both EV versus cells and non-EV versus cells comparisons (Figure $4 \mathrm{c}-\mathrm{f}$, bright blue branches). This suggests that certain high-expressing miRNAs are likely to be retained in cells via an unknown mechanism. 
a
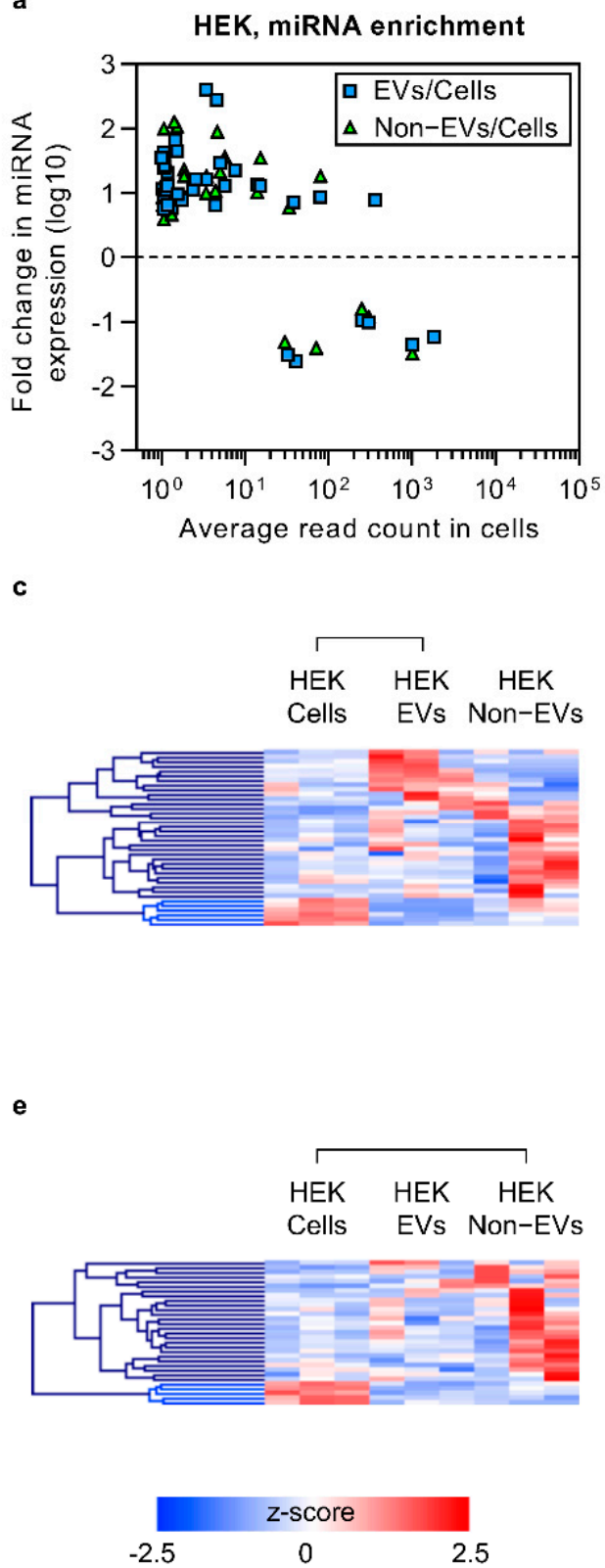

b

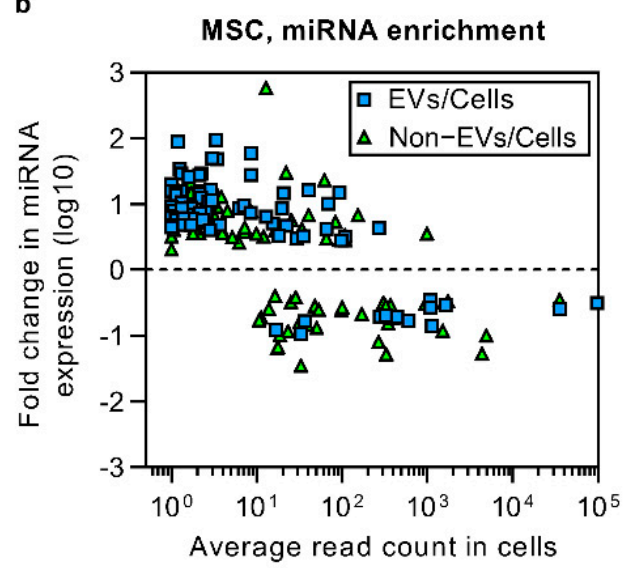

d

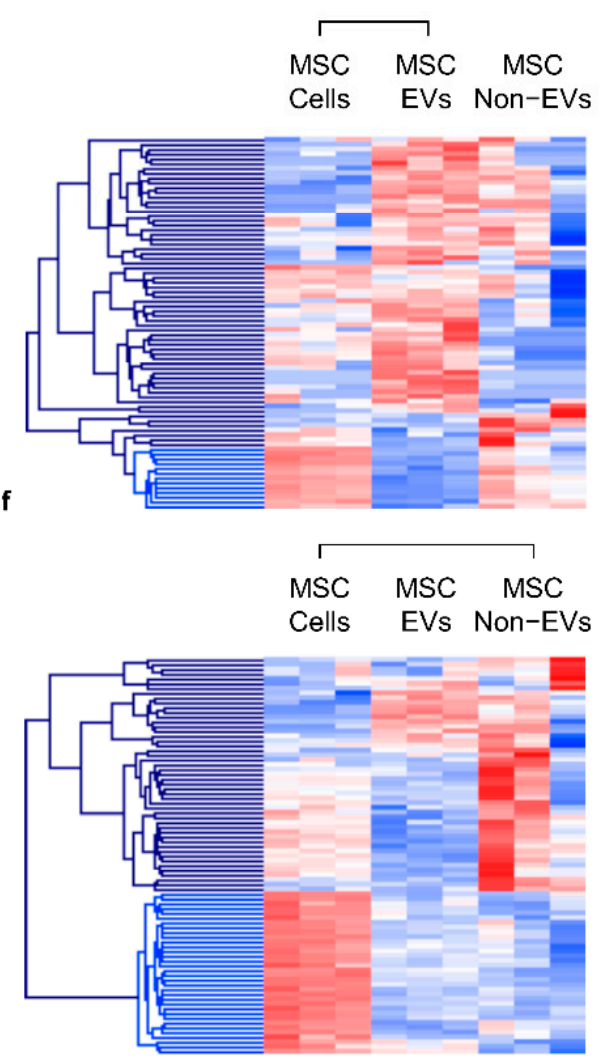

Figure 4. The enrichment pattern of secretory miRNAs as compared to source cells. (a,b) miRNA relative enrichment analysis revealed that those miRNAs that were enriched in EVs and Non-EVs had a low average read count in cells. This is true in both HEK as well as MSC samples. (c-f) Heat maps of hierarchical clustering analysis further suggested that certain miRNAs are restricted from secretion, as miRNAs enriched in cells were reduced in both the EV and Non-EV fractions. Also, the enrichment of miRNAs in EVs was generally not mirrored in the Non-EV fraction. The connecting lines in c-f denote pairwise sample comparisons.

\subsection{The Bulk of Extracellular miRNAs Are Secreted via Non-EV Route}

From the sequencing results, we could conclude that the enrichment of short RNA sequences at their basal level into EVs can mainly be seen for lowly expressed sequences. To validate these findings with an alternative methodology, we focused on miRNAs with a wide basal expression range (and hence potentially different secretion enrichment characteristics). We selected five miRNAs from our data set (miR-100, miR-210, miR-16, miR-21 
and miR-186) and quantified their secretion level by RT-qPCR. As compared to source cells, the level of miR-100 and miR-21 was higher in the extracellular space for HEK cells and lower for MSCs (Supplementary Material Tables S1 and S2), whereas no significant changes were detected in secreted miR-210, miR-16 and miR-186 (Supplementary Material Tables S1 and S2). Nevertheless, regardless of the basal expression and secretory enrichment level of tested miRNAs, similarly to overexpression experiments, only a very small proportion of total secreted miRNAs was found to be associated with EVs. More specifically, only $0.1-0.4 \%$ and $0.9-3.8 \%$ of miRNA sequences were detected in EVs of HEK- and MSCderived conditioned medium, respectively (Figure 5a,b). Thus, a striking 96.2-99.9\% of extracellular miRNAs were secreted in association with non-EV carriers, underpinning the need for active strategies to enforce vesicular miRNA loading.

$\mathbf{a}$

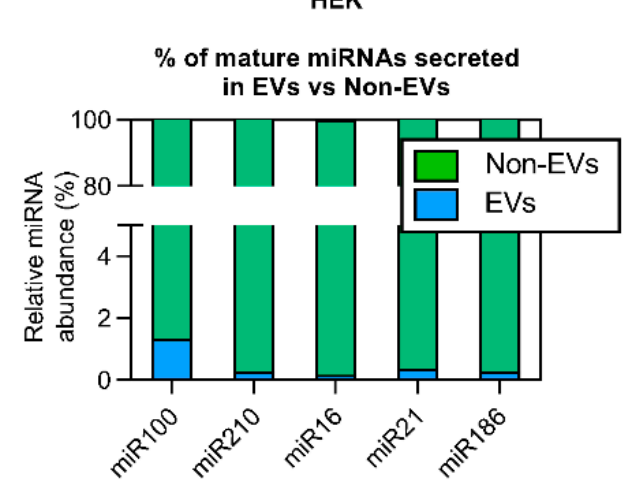

b

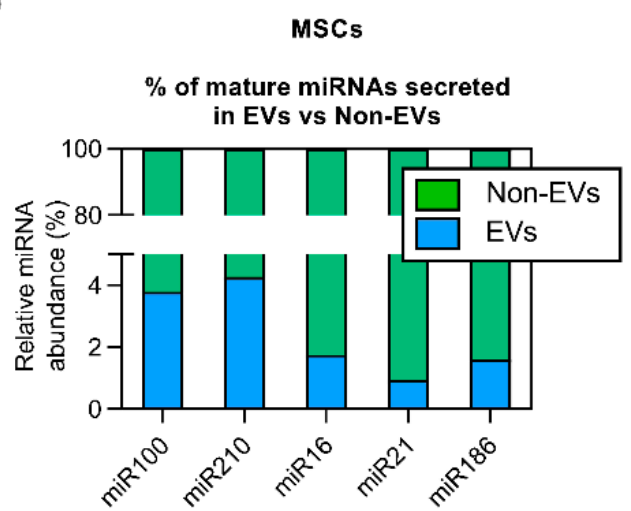

Figure 5. RT-qPCR quantification of mature miRNAs from EV and Non-EV fractions at their basal cellular expression level. Regardless of relative miRNA enrichment levels, the majority of secreted miRNAs are found outside of EVs both in HEK (a), and MSC (b) samples and the Non-EV material contains a striking $96-99 \%$ of total secreted miRNAs.

\section{Discussion}

The extracellular space consists of multiple types of nucleic acid carriers, including EVs, which are one of the most actively studied fractions of the secretome. EVs contain many different types of RNA and, as widely demonstrated, transfer it in a biologically active form [48-50]. Owing to the RNA transfer capacity, EVs are actively developed as carriers of biotherapeutic RNA molecules, such as miRNAs and shRNAs. Since the overall abundance of specific miRNA molecules in EVs is low and only a small fraction of all EVs contain a given miRNA sequence [30-32], a lot of effort is directed towards enriching EVs with therapeutic miRNA and shRNA sequences, often by overexpressing them in EV producer cells. Owing to studies often using ultracentrifugation (UC) for EV isolation, it is known that certain RNA stretches are rather secreted independently of EVs $[14,15]$. Yet, it must be noted that incomplete EV pelleting in centrifugation-based approaches perplexes the interpretation of those results, indicating the need to employ more refined methodologies for dissecting the secretome [51,52].

The study at hand employed a well-established secretome fractionation strategy, SEC, in order to explore the relative distribution of short RNA stretches in EVs and non-EV secretory fractions. Our preliminary observations in the RNA overexpression context showed that $<2 \%$ of analyzed miRNAs were secreted via EVs, while the great majority of overexpressed miRNA ended up in the non-EV fraction, corroborating with a recent study showing similar findings from virus-infected cells [53]. Moreover, the low EV-miRNA amount was observed irrespective of the overexpression type, using either CMV or U6 promoter and pri-miRNAs/shRNAs for loading the EVs, as often used for therapeutic RNA loading into EVs [35,54-57]. This indicates that the passive overexpression strategy could be a rather wasteful way for loading EVs with RNA cargo molecules. Also, similarly 
to our previous findings [16], the overexpressed EV miRNA was fully processed and stable in a serum-containing environment for up to $24 \mathrm{~h}$. Yet, despite this greatly exceeding the half-life of EVs in vivo [58-61], the low miRNA level is still unlikely to have satisfactory therapeutic potential.

Owing to the insufficient systematic knowledge on how short RNA sequences are secreted in the global context on the basal level, it is difficult to design robust universal strategies for miRNA enrichment in EVs. Though a number of small RNA sequencing studies have been performed to define the exact nucleic acid composition of EVs, the majority thus far exploit UC-based EV enrichment protocols [32,62-64]. Further complexity in studying EV-RNA arises from the low overall abundance of specific miRNA molecules in EVs [30-32,53] and the knowledge that sRNAs cover only the minority of reads, even when concentrating on studying short sequences $[38,46]$. Another aspect in such global analysis is the presence of bovine serum-derived miRNAs, which can contaminate both EV and nonEV samples when EV-depleted serum is used $[42,43,65]$. Though this can successfully be overcome by using Opti-MEM-based serum-free media, it must be considered that altering the culturing conditions might change the transcriptome of cells and therefore also affect the contents of EVs, as seen previously $[44,66]$. To minimize the potential risks of changes in EV content and contaminating RNA originating from EV-depleted serum [42,43], the study at hand conducted parallel comparisons (i.e., the cell, EV and non-EV samples were collected from within the same experiment) and used Opti-MEM-based serum-free media for EV production, respectively.

To follow up on the aforementioned overexpression work, we continued to use SEC, separated the secretome of HEK cells and MSCs into the EV and non-EV fractions and aimed to characterize the global sRNA sorting at the basal expression level. The preliminary clustering analysis showed a clear separation between cellular, EV and non-EV samples. While this suggested global differences, the content of EVs and non-EVs appeared to be more similar to each other than to their source cells. A closer look at different short RNA biotypes revealed that the similarity might be attributed to piRNA sequences, of which the cells were relatively depleted, as well as to miRNAs, being highly prevalent in cells and less abundant in the secretory fractions. Nevertheless, the miRNA expression both in EVs and non-EVs correlated highly to that of their parent cells, suggesting that in general, the most important factor determining the level of secreted miRNA is its expression level in the source cells. This does not, however mean that miRNA sequences cannot be enriched in EVs, as certain proteins mediating miRNA sorting into EVs, such as hnRNP-Q, hnRNPA2B1 and major vault protein, have been suggested [67-69]. Yet, according to a recent report, "classical" EVs are devoid of these RNA-binding proteins [70], with parallel studies suggesting Lupus La protein involvement in miRNA sorting and the simultaneous presence of selective as well as non-selective miRNA sorting mechanisms, possibly depending on the origin of EVs [71]. Similarly, to those observations, compared to source cells, we also noticed a relative enrichment of certain miRNA sequences in EVs as well as in the non-EV fraction. Interestingly, these sequences were expressed in HEK cells and MSCs at a low level, whereas the secretion of highly-expressed miRNAs was generally not enriched. Hence, in accordance with recent reports, the data at hand suggests an overall average stochastic secretion mechanism with evidence on selective sorting in the case of some miRNAs.

Importantly, we must underline that even if a specific sequence was enriched in EVs versus non-EVs in relative terms, the total abundance of miRNAs in the non-EV fraction, in fact, greatly exceeded that of EVs. Though similar evidence has been reported previously by others, often by using UC for EV isolation [14,15], we were now able to confirm these observations on SEC-purified secretome fractions by using RT-qPCR. In the cell culture supernatants of HEK cells, we found less than $2 \%$ of miRNAs in EVs, whereas over $98 \%$ of miRNA was found in the non-EV fraction. MSC-derived samples contained slightly more miRNAs in EVs; however, over $96 \%$ of miRNAs were still secreted in the non-EVs fraction. This could, on the one hand, reflect the inherent differences in cell line-dependent packaging 
mechanisms, or else hint to mechanisms modulating the preservation of basal therapeutic potential of MSC EV miRNAs [72,73]. Moreover, we saw that the basal expression and secretory enrichment level of miRNAs are irrelevant to their overall accumulation in EVs, as the secretion is nonetheless heavily inclined towards the non-EV pool. Considering our aforementioned observation that even miRNA/shRNA overexpression is unable to reroute the miRNAs to the EVs, transient overexpression strategy seems to be uneconomic for loading EVs with RNA cargo. Though sequences with low basal expression levels ought to give better results in terms of expression level increase, and even if significant enrichment is achieved, the bulk material will still not end up in EVs. Overall this pinpoints that without active EV-targeted loading strategies, the level of a given miRNA in the vesicles will most probably not reach a therapeutically relevant scale.

Supplementary Materials: The following are available online at https:/ /www.mdpi.com/article/ 10.3390/cells10061543/s1, Figure S1: EV characterization. Figure S2: Further validation of the SEC workflow for separating EV and non-EV secreted material using Neuro2a cells after overexpression of let-7a miRNA. Figure S3: sRNA composition, characteristics and enrichment in secretory fractions. Figure S4: Read alignment, annotation and length statistics across the studies samples. Figure S5: The prevalence of 'other RNA' biotypes. Figure S6: Length distribution histograms for reads aligning to miRNAs. Figure S7: Correlation plots of all mature miRNAs. Figure S8: Heatmaps of differentially expressed miRNAs detected between the EV and Non-EV fraction of the MSC (A) and HEK (B) secretome. Table S1: Differentially expressed miRNAs in EVs vs. Cells. Table S2: Differentially expressed miRNAs in Non-EVs vs. Cells. Table S3: Differentially expressed miRNAs in EV vs. Non-EV samples.

Author Contributions: Conceptualization, I.M. and S.E.A.; Project administration, H.S. and I.M.; Investigation and Validation, H.S., M.C., G.C., J.N., Y.X.F.L., K.K., P.V., M.P. and I.M.; Formal analysis, H.S., M.C., G.C., M.P. and I.M.; Visualization, H.S. and I.M.; Software, H.S. and J.O.W.; Supervision, J.O.W., P.V., R.E.V., M.J.W., S.E.A. and I.M.; Resources, S.E.A. and M.J.W.; Funding acquisition, H.S., M.C., G.C., Y.X.F.L., J.O.W., S.E.A. and M.J.W.; Writing—original draft preparation, H.S. and I.M., Writing - review and editing, all authors. All authors have read and agreed to the published version of the manuscript.

Funding: This work was supported by the national scholarship program Kristjan Jaak, which is funded and managed by the Archimedes Foundation in collaboration with the Estonian Ministry of Education and Research [H.S.]; the European Regional Development Fund and the program Mobilitas Pluss (MOBJD512) [H.S.]; KID-funding (Karolinska Institutet doctoral co-financing agreement with the Stockholm County Council) [G.C.]; the Agency for Science Technology and Research (A*STAR), Singapore [Y.X.F.L.]; Knut and Alice Wallenberg Foundation as part of the National Bioinformatics Infrastructure Sweden at SciLifeLab [J.O.W.]; Swedish Research Council (VR_med), the Swedish Society of Medical Research (SSMF) and SSF [S.E.A.]; Estonian Research Council PUT program PUT618 [I.M.], EU IMI COMPACT Consortium [I.M.], EU Horizon 2020 B-SMART Consortium No 721058 [I.M.], John Fell Fund [M.C., I.M.]; MRC and BBSRC [S.E.A., M.J.W.].

Institutional Review Board Statement: Not applicable.

Informed Consent Statement: Not applicable.

Data Availability Statement: The small RNA sequencing data has been deposited to NCBI Sequence Read Archives under BioProject ID PRJNA738841.

Acknowledgments: The authors would like to acknowledge support from Science for Life Laboratory, the National Genomics Infrastructure and Uppmax for providing assistance in massive parallel sequencing and computational infrastructure. We would also like to thank Marc Friedländer and Wenjing Kang for their assistance in the bioinformatic data analysis.

Conflicts of Interest: J.N., M.J.W. and S.E.A. are shareholders and consultants for Evox Therapeutics Ltd. P.V. serves on the scientific advisory board of Evox Therapeutics Ltd. 


\section{References}

1. Kahlert, C.; Melo, S.A.; Protopopov, A.; Tang, J.; Seth, S.; Koch, O.; Zhang, J.; Weitz, J.; Chin, L.; Futreal, A.; et al. Identification of doublestranded genomic dna spanning all chromosomes with mutated KRAS and P53 DNA in the serum exosomes of patients with pancreatic cancer. J. Biol. Chem. 2014, 289, 3869-3875. [CrossRef]

2. Huang, X.; Yuan, T.; Tschannen, M.; Sun, Z.; Jacob, H.; Du, M.; Liang, M.M.; Dittmar, R.L.; Liu, Y.; Liang, M.M.; et al. Characterization of human plasma-derived exosomal RNAs by deep sequencing. BMC Genom. 2013, 14, 319. [CrossRef] [PubMed]

3. Vojtech, L.; Woo, S.; Hughes, S.; Levy, C.; Ballweber, L.; Sauteraud, R.P.; Strobl, J.; Westerberg, K.; Gottardo, R.; Tewari, M.; et al. Exosomes in human semen carry a distinctive repertoire of small non-coding RNAs with potential regulatory functions. Nucleic Acids Res. 2014, 42, 7290-7304. [CrossRef]

4. Ohno, S.I.; Takanashi, M.; Sudo, K.; Ueda, S.; Ishikawa, A.; Matsuyama, N.; Fujita, K.; Mizutani, T.; Ohgi, T.; Ochiya, T.; et al. Systemically injected exosomes targeted to EGFR deliver antitumor microrna to breast cancer cells. Mol. Ther. 2013, 21, 185-191. [CrossRef] [PubMed]

5. Alvarez-Erviti, L.; Seow, Y.; Yin, H.; Betts, C.; Lakhal, S.; Wood, M.J.A. Delivery of siRNA to the mouse brain by systemic injection of targeted exosomes. Nat. Biotechnol. 2011, 29, 341-345. [CrossRef] [PubMed]

6. Pi, F.; Binzel, D.W.; Lee, T.J.; Li, Z.; Sun, M.; Rychahou, P.; Li, H.; Haque, F.; Wang, S.; Croce, C.M.; et al. Nanoparticle orientation to control RNA loading and ligand display on extracellular vesicles for cancer regression. Nat. Nanotechnol. 2018, 13, 82-89. [CrossRef] [PubMed]

7. Kamerkar, S.; Lebleu, V.S.; Sugimoto, H.; Yang, S.; Ruivo, C.F.; Melo, S.A.; Lee, J.J.; Kalluri, R. Exosomes facilitate therapeutic targeting of oncogenic KRAS in pancreatic cancer. Nature 2017, 546, 498-503. [CrossRef]

8. $\quad$ Didiot, M.C.; Hall, L.M.; Coles, A.H.; Haraszti, R.A.; Godinho, B.M.D.C.; Chase, K.; Sapp, E.; Ly, S.; Alterman, J.F.; Hassler, M.R.; et al. Exosome-mediated delivery of hydrophobically modified siRNA for huntingtin mRNA silencing. Mol. Ther. 2016, 24, 1836-1847. [CrossRef] [PubMed]

9. Lee, S.-T.; Im, W.; Ban, J.-J.; Lee, M.; Jung, K.-H.; Lee, S.K.; Chu, K.; Kim, M. Exosome-Based Delivery of miR-124 in a Huntington's Disease Model. J. Mov. Disord. 2017, 10, 45-52. [CrossRef] [PubMed]

10. Kosaka, N.; Iguchi, H.; Yoshioka, Y.; Takeshita, F.; Matsuki, Y.; Ochiya, T. Secretory mechanisms and intercellular transfer of microRNAs in living cells. J. Biol. Chem. 2010, 285, 17442-17452. [CrossRef] [PubMed]

11. Kosaka, N.; Iguchi, H.; Yoshioka, Y.; Hagiwara, K.; Takeshita, F.; Ochiya, T. Competitive interactions of cancer cells and normal cells via secretory microRNAs. J. Biol. Chem. 2012, 287, 1397-1405. [CrossRef] [PubMed]

12. Vickers, K.C.; Palmisano, B.T.; Shoucri, B.M.; Shamburek, R.D.; Remaley, A.T. MicroRNAs are Transported in Plasma and Delivered to Recipient Cells by High-Density Lipoproteins. Nat Cell Biol. 2011, 13, 423-433. [CrossRef] [PubMed]

13. Arroyo, J.D.; Chevillet, J.R.; Kroh, E.M.; Ruf, I.K.; Pritchard, C.C.; Gibson, D.F.; Mitchell, P.S.; Bennett, C.F.; Pogosova-Agadjanyan, E.L.; Stirewalt, D.L.; et al. Argonaute2 complexes carry a population of circulating microRNAs independent of vesicles in human plasma. Proc. Natl. Acad. Sci. USA 2011, 108, 5003-5008. [CrossRef] [PubMed]

14. Wang, K.; Zhang, S.; Weber, J.; Baxter, D.; Galas, D.J. Export of microRNAs and microRNA-protective protein by mammalian cells. Nucleic Acids Res. 2010, 38, 7248-7259. [CrossRef]

15. Turchinovich, A.; Weiz, L.; Langheinz, A.; Burwinkel, B. Characterization of extracellular circulating microRNA. Nucleic Acids Res. 2011, 39, 7223-7233. [CrossRef] [PubMed]

16. Coenen-Stass, A.M.L.; Pauwels, M.J.; Hanson, B.; Martin Perez, C.; Conceição, M.; Wood, M.J.A.; Mäger, I.; Roberts, T.C. Extracellular microRNAs exhibit sequence-dependent stability and cellular release kinetics. RNA Biol. 2019, 16, 696-706. [CrossRef]

17. Sanchez, M.B.H.; Bruno, S.; Grange, C.; Tapparo, M.; Cantaluppi, V.; Tetta, C.; Camussi, G. Human liver stem cells and derived extracellular vesicles improve recovery in a murine model of acute kidney injury. Stem Cell Res. Ther. 2014, 5. [CrossRef]

18. Fuentes, P.; Sesé, M.; Guijarro, P.J.; Emperador, M.; Sánchez-Redondo, S.; Peinado, H.; Hümmer, S.; Ramón, y.; Cajal, S. ITGB3mediated uptake of small extracellular vesicles facilitates intercellular communication in breast cancer cells. Nat. Commun. 2020, 11. [CrossRef]

19. Lee, C.; Mitsialis, S.A.; Aslam, M.; Vitali, S.H.; Vergadi, E.; Konstantinou, G.; Sdrimas, K.; Fernandez-Gonzalez, A.; Kourembanas, $\mathrm{S}$. Exosomes mediate the cytoprotective action of mesenchymal stromal cells on hypoxia-induced pulmonary hypertension. Circulation 2012, 126, 2601-2611. [CrossRef]

20. Valadi, H.; Ekström, K.; Bossios, A.; Sjöstrand, M.; Lee, J.J.; Lötvall, J.O. Exosome-mediated transfer of mRNAs and microRNAs is a novel mechanism of genetic exchange between cells. Nat. Cell Biol. 2007, 9, 654-659. [CrossRef]

21. Ratajczak, J.; Miekus, K.; Kucia, M.; Zhang, J.; Reca, R.; Dvorak, P.; Ratajczak, M.Z. Embryonic stem cell-derived microvesicles reprogram hematopoietic progenitors: Evidence for horizontal transfer of mRNA and protein delivery. Leukemia 2006, 20, 847-856. [CrossRef]

22. Skog, J.; Würdinger, T.; van Rijn, S.; Meijer, D.H.; Gainche, L.; Sena-Esteves, M.; Curry, W.T.; Carter, B.S.; Krichevsky, A.M.; Breakefield, X.O. Glioblastoma microvesicles transport RNA and proteins that promote tumour growth and provide diagnostic biomarkers. Nat. Cell Biol. 2008, 10, 1470-1476. [CrossRef] [PubMed] 
23. Thomou, T.; Mori, M.A.; Dreyfuss, J.M.; Konishi, M.; Sakaguchi, M.; Wolfrum, C.; Rao, T.N.; Winnay, J.N.; Garcia-Martin, R.; Grinspoon, S.K.; et al. Adipose-derived circulating miRNAs regulate gene expression in other tissues. Nature 2017, 542, 450-455. [CrossRef] [PubMed]

24. Ying, W.; Riopel, M.; Bandyopadhyay, G.; Dong, Y.; Birmingham, A.; Seo, J.B.; Ofrecio, J.M.; Wollam, J.; Hernandez-Carretero, A.; Fu, W.; et al. Adipose Tissue Macrophage-Derived Exosomal miRNAs Can Modulate in Vivo and in Vitro Insulin Sensitivity. Cell 2017, 171, 372-384. [CrossRef]

25. Mittelbrunn, M.; Gutiérrez-Vázquez, C.; Villarroya-Beltri, C.; González, S.; Sánchez-Cabo, F.; González, M.Á.; Bernad, A.; Sánchez-Madrid, F. Unidirectional transfer of microRNA-loaded exosomes from T cells to antigen-presenting cells. Nat. Commun. 2011, 2, 282. [CrossRef]

26. Mizrak, A.; Bolukbasi, M.F.; Ozdener, G.B.; Brenner, G.J.; Madlener, S.; Erkan, E.P.; Ströbel, T.; Breakefield, X.O.; Saydam, O. Genetically engineered microvesicles carrying suicide mRNA/protein inhibit schwannoma tumor growth. Mol. Ther. 2013, 21, 101-108. [CrossRef]

27. Möbius, W.; van Donselaar, E.; Ohno-Iwashita, Y.; Shimada, Y.; Heijnen, H.F.G.; Slot, J.W.; Geuze, H.J. Recycling compartments and the internal vesicles of multivesicular bodies harbor most of the cholesterol found in the endocytic pathway. Traffic 2003, 4 , 222-231. [CrossRef]

28. Lou, G.; Yang, Y.; Liu, F.; Ye, B.; Chen, Z.; Zheng, M.; Liu, Y. MiR-122 modification enhances the therapeutic efficacy of adipose tissue-derived mesenchymal stem cells against liver fibrosis. J. Cell. Mol. Med. 2017. [CrossRef] [PubMed]

29. Chen, L.; Lu, F.-B.; Chen, D.-Z.; Wu, J.-L.; Hu, E.; Xu, L.-M.; Zheng, M.-H.; Li, H.; Huang, Y.; Jin, X.-Y.; et al. BMSCs-derived miR-223-containing exosomes contribute to liver protection in experimental autoimmune hepatitis. Mol. Immunol. 2018, 93, 38-46. [CrossRef]

30. Chevillet, J.R.; Kang, Q.; Ruf, I.K.; Briggs, H.A.; Vojtech, L.N.; Hughes, S.M.; Cheng, H.H.; Arroyo, J.D.; Meredith, E.K.; Gallichotte, E.N.; et al. Quantitative and stoichiometric analysis of the microRNA content of exosomes. Proc. Natl. Acad. Sci. USA 2014, 111, 14888-14893. [CrossRef]

31. Van Eijndhoven, M.A.J.; Zijlstra, J.M.; Groenewegen, N.J.; Drees, E.E.E.; van Niele, S.; Baglio, S.R.; Koppers-Lalic, D.; van der Voorn, H.; Libregts, S.F.W.M.; Wauben, M.H.M.; et al. Plasma vesicle miRNAs for therapy response monitoring in Hodgkin lymphoma patients. JCI Insight 2016, 1, e89631. [CrossRef] [PubMed]

32. Tosar, J.P.; Gámbaro, F.; Sanguinetti, J.; Bonilla, B.; Witwer, K.W.; Cayota, A. Assessment of small RNA sorting into different extracellular fractions revealed by high-throughput sequencing of breast cell lines. Nucleic Acids Res. 2015, 43, 5601-5616. [CrossRef]

33. Wei, Z.; Batagov, A.O.; Schinelli, S.; Wang, J.; Wang, Y.; El Fatimy, R.; Rabinovsky, R.; Balaj, L.; Chen, C.C.; Hochberg, F.; et al. Coding and noncoding landscape of extracellular RNA released by human glioma stem cells. Nat. Commun. 2017, 8, 1145. [CrossRef] [PubMed]

34. Diederichs, S.; Haber, D.A. Sequence variations of microRNAs in human cancer: Alterations in predicted secondary structure do not affect processing. Cancer Res. 2006, 66, 6097-6104. [CrossRef] [PubMed]

35. Vader, P.; Mäger, I.; Lee, Y.; Nordin, J.Z.; Andaloussi, S.E.L.; Wood, M.J.A. Preparation and isolation of siRNA-loaded extracellular vesicles. In Methods in Molecular Biology; Humana Press: New York, NY, USA, 2017; Volume 1545, pp. 197-204.

36. Nordin, J.Z.; Lee, Y.; Vader, P.; Mäger, I.; Johansson, H.J.; Heusermann, W.; Wiklander, O.P.B.; Hällbrink, M.; Seow, Y.; Bultema, J.J.; et al. Ultrafiltration with size-exclusion liquid chromatography for high yield isolation of extracellular vesicles preserving intact biophysical and functional properties. Nanomed. Nanotechnol. Biol. Med. 2015, 11, 879-883. [CrossRef]

37. Corso, G.; Mäger, I.; Lee, Y.; Görgens, A.; Bultema, J.; Giebel, B.; Wood, M.J.A.; Nordin, J.Z.; Andaloussi, S. El Reproducible and scalable purification of extracellular vesicles using combined bind-elute and size exclusion chromatography. Sci. Rep. 2017, 7, 11561. [CrossRef] [PubMed]

38. Sork, H.; Corso, G.; Krjutskov, K.; Johansson, H.J.; Nordin, J.Z.; Wiklander, O.P.B.; Lee, Y.X.F.; Westholm, J.O.; Lehtiö, J.; Wood, M.J.A.; et al. Heterogeneity and interplay of the extracellular vesicle small RNA transcriptome and proteome. Sci. Rep. 2018, 8 , 10813. [CrossRef]

39. RStudioTeam. RStudio: Integrated Development Environment for R. Available online: http://www.rstudio.com/ (accessed on 25 April 2021).

40. Love, M.I.; Huber, W.; Anders, S. Moderated estimation of fold change and dispersion for RNA-seq data with DESeq2. Genome Biol. 2014, 15, 550. [CrossRef]

41. Saeed, A.I.; Sharov, V.; White, J.; Li, J.; Liang, W.; Bhagabati, N.; Braisted, J.; Klapa, M.; Currier, T.; Thiagarajan, M.; et al. TM4: A free, open-source system for microarray data management and analysis. Biotechniques 2003, 34, 374-378. [CrossRef]

42. Tosar, J.P.; Cayota, A.; Eitan, E.; Halushka, M.K.; Witwer, K.W. Ribonucleic artefacts: Are some extracellular RNA discoveries driven by cell culture medium components? J. Extracell. Vesicles 2017, 6, 1272832. [CrossRef]

43. Mannerström, B.; Paananen, R.O.; Abu-Shahba, A.G.; Moilanen, J.; Seppänen-Kaijansinkko, R.; Kaur, S. Extracellular small non-coding RNA contaminants in fetal bovine serum and serum-free media. Sci. Rep. 2019, 9, 5538. [CrossRef]

44. Li, J.; Lee, Y.; Johansson, H.J.; Mäger, I.; Vader, P.; Nordin, J.Z.; Wiklander, O.P.B.; Lehtiö, J.; Wood, M.J.A.; El Andaloussi, S. Serum-free culture alters the quantity and protein composition of neuroblastoma-derived extracellular vesicles. J. Extracell. Vesicles 2015, 4, 1-12. [CrossRef] 
45. Willms, E.; Johansson, H.J.; Mäger, I.; Lee, Y.; Blomberg, K.E.M.; Sadik, M.; Alaarg, A.; Smith, C.I.I.E.; Lehtiö, J.; El Andaloussi, S.; et al. Cells release subpopulations of exosomes with distinct molecular and biological properties. Sci. Rep. 2016, 6, 22519. [CrossRef]

46. Nolte-'t Hoen, E.N.M.; Buermans, H.P.J.; Waasdorp, M.; Stoorvogel, W.; Wauben, M.H.M.; 't Hoen, P.A.C.; Hoen, P.A.C. Deep sequencing of RNA from immune cell-derived vesicles uncovers the selective incorporation of small non-coding RNA biotypes with potential regulatory functions. Nucleic Acids Res. 2012, 40, 9272-9285. [CrossRef]

47. Lässer, C.; Shelke, G.V.; Yeri, A.; Kim, D.-K.; Crescitelli, R.; Raimondo, S.; Sjöstrand, M.; Gho, Y.S.; Van Keuren Jensen, K.; Lötvall, J. Two distinct extracellular RNA signatures released by a single cell type identified by microarray and next-generation sequencing. RNA Biol. 2016, 14, 58-72. [CrossRef]

48. Moghaddam, A.S.; Afshari, J.T.; Esmaeili, S.A.; Saburi, E.; Joneidi, Z.; Momtazi-Borojeni, A.A. Cardioprotective microRNAs: Lessons from stem cell-derived exosomal microRNAs to treat cardiovascular disease. Atherosclerosis 2019, 285, 1-9. [CrossRef] [PubMed]

49. Schwarzenbach, H.; Gahan, P.B. MicroRNA shuttle from cell-to-cell by exosomes and its impact in cancer. Non-Coding RNA 2019, 5, 28. [CrossRef] [PubMed]

50. Coenen-Stass, A.M.L.; Mäger, I.; Wood, M.J.A. Extracellular microRNAs in Membrane Vesicles and Non-Vesicular Carriers; Springer: Basel, Switzerland, 2015; ISBN 978-3-0348-0955-9.

51. Cvjetkovic, A.; Lötvall, J.; Lässer, C. The influence of rotor type and centrifugation time on the yield and purity of extracellular vesicles. J. Extracell. Vesicles 2014, 3, 23111. [CrossRef]

52. Livshts, M.A.; Khomyakova, E.; Evtushenko, E.G.; Lazarev, V.N.; Kulemin, N.A.; Semina, S.E.; Generozov, E.V.; Govorun, V.M. Isolation of exosomes by differential centrifugation: Theoretical analysis of a commonly used protocol. Sci. Rep. 2015, 5, 17319. [CrossRef] [PubMed]

53. Albanese, M.; Chen, Y.-F.A.; Hüls, C.; Gärtner, K.; Tagawa, T.; Mejias-Perez, E.; Keppler, O.; Göbel, C.; Zeidler, R.; Shein, M.; et al Micro RNAs are minor constituents of extracellular vesicles and are hardly delivered to target cells. bioRxiv 2020. [CrossRef]

54. Lamichhane, T.N.; Jay, S.M. Production of Extracellular Vesicles Loaded with Therapeutic Cargo. Methods Mol. Biol. 2018, 1831, 37-47. [CrossRef]

55. Maheshwari, R.; Tekade, M.; Gondaliya, P.; Kalia, K.; D’Emanuele, A.; Tekade, R.K. Recent advances in exosome-based nanovehicles as RNA interference therapeutic carriers. Nanomedicine 2017. [CrossRef]

56. Shahabipour, F.; Barati, N.; Johnston, T.P.; Derosa, G.; Maffioli, P.; Sahebkar, A. Exosomes: Nanoparticulate tools for RNA interference and drug delivery. J. Cell. Physiol. 2017, 232, 1660-1668. [CrossRef]

57. Kumar, L.; Verma, S.; Vaidya, B.; Gupta, V. Exosomes: Natural Carriers for siRNA Delivery. Curr. Pharm. Des. 2015, 21, 4556-4565. [CrossRef]

58. Göran Ronquist, K. Extracellular vesicles and energy metabolism. Clin. Chim. Acta. 2019, 488, 116-121. [CrossRef]

59. Morishita, M.; Takahashi, Y.; Nishikawa, M.; Takakura, Y. Pharmacokinetics of Exosomes-An Important Factor for Elucidating the Biological Roles of Exosomes and for the Development of Exosome-Based Therapeutics. J. Pharm. Sci. 2017, 106, 2265-2269. [CrossRef]

60. Gangadaran, P.; Hong, C.M.; Ahn, B.C. Current Perspectives on in Vivo Noninvasive Tracking of Extracellular Vesicles with Molecular Imaging. BioMed Res. Int. 2017, 2017, 9158319. [CrossRef] [PubMed]

61. Wiklander, O.P.B.; Brennan, M.Á.; Lötvall, J.; Breakefield, X.O.; Andaloussi, S.E.L.; El Andaloussi, S. Advances in therapeutic applications of extracellular vesicles. Sci. Transl. Med. 2019, 11, eaav8521. [CrossRef]

62. Van Balkom, B.W.M.; Eisele, A.S.; Pegtel, D.M.; Bervoets, S.; Verhaar, M.C. Quantitative and qualitative analysis of small RNAs in human endothelial cells and exosomes provides insights into localized RNA processing, degradation and sorting. J. Extracell. Vesicles 2015, 4, 1-14. [CrossRef] [PubMed]

63. Miranda, K.C.; Bond, D.T.; Levin, J.Z.; Adiconis, X.; Sivachenko, A.; Russ, C.; Brown, D.; Nusbaum, C.; Russo, L.M. Massively parallel sequencing of human urinary exosome/microvesicle RNA reveals a predominance of non-coding RNA. PLoS ONE 2014, 9, e96094. [CrossRef] [PubMed]

64. Guduric-Fuchs, J.; O'Connor, A.; Camp, B.; O’Neill, C.L.; Medina, R.J.; Simpson, D.A. Selective extracellular vesicle-mediated export of an overlapping set of microRNAs from multiple cell types. BMC Genomics 2012, 13, 357. [CrossRef] [PubMed]

65. Wei, Z.; Batagov, A.O.; Carter, D.R.F.; Krichevsky, A.M.; Quinn, J.F.; Landgraf, P.; Ludwig, N.; Agrawal, R.; Villarroya-Beltri, C.; Pigati, L.; et al. Fetal Bovine Serum RNA Interferes with the Cell Culture derived Extracellular RNA. Sci. Rep. 2016, 6, 31175. [CrossRef] [PubMed]

66. Aswad, H.; Jalabert, A.; Rome, S. Depleting extracellular vesicles from fetal bovine serum alters proliferation and differentiation of skeletal muscle cells in vitro. BMC Biotechnol. 2016, 16, 32. [CrossRef]

67. Santangelo, L.; Giurato, G.; Cicchini, C.; Montaldo, C.; Mancone, C.; Tarallo, R.; Battistelli, C.; Alonzi, T.; Weisz, A.; Tripodi, M. The RNA-Binding Protein SYNCRIP Is a Component of the Hepatocyte Exosomal Machinery Controlling MicroRNA Sorting. Cell Rep. 2016, 17, 799-808. [CrossRef] [PubMed]

68. Villarroya-Beltri, C.; Gutiérrez-Vázquez, C.; Sánchez-Cabo, F.; Pérez-Hernández, D.; Vázquez, J.; Martin-Cofreces, N.; MartinezHerrera, D.J.; Pascual-Montano, A.; Mittelbrunn, M.; Sánchez-Madrid, F. Sumoylated hnRNPA2B1 controls the sorting of miRNAs into exosomes through binding to specific motifs. Nat. Commun. 2013, 4, 2980. [CrossRef] 
69. Teng, Y.; Ren, Y.; Hu, X.; Mu, J.; Samykutty, A.; Zhuang, X.; Deng, Z.; Kumar, A.; Zhang, L.; Merchant, M.L.; et al. MVP-mediated exosomal sorting of miR-193a promotes colon cancer progression. Nat. Commun. 2017, 8, 14448. [CrossRef] [PubMed]

70. Jeppesen, D.K.; Fenix, A.M.; Franklin, J.L.; Higginbotham, J.N.; Zhang, Q.; Zimmerman, L.J.; Liebler, D.C.; Ping, J.; Liu, Q.; Evans, R.; et al. Reassessment of Exosome Composition. Cell 2019, 177, 428-445. [CrossRef]

71. Temoche-Diaz, M.M.; Shurtleff, M.J.; Nottingham, R.M.; Yao, J.; Fadadu, R.P.; Lambowitz, A.M.; Schekman, R. Distinct mechanisms of microrna sorting into cancer cell-derived extracellular vesicle subtypes. Elife 2019, 8. [CrossRef]

72. Wen, S.; Dooner, M.; Cheng, Y.; Papa, E.; Del Tatto, M.; Pereira, M.; Deng, Y.; Goldberg, L.; Aliotta, J.; Chatterjee, D.; et al. Mesenchymal stromal cell derived extracellular vesicles rescue radiation damage to murine marrow hematopoietic cells. Leukemia 2016, 30, 2221-2231. [CrossRef]

73. Zhang, Y.; Chopp, M.; Zhang, Z.G.; Katakowski, M.; Xin, H.; Qu, C.; Ali, M.; Mahmood, A.; Xiong, Y. Systemic administration of cell-free exosomes generated by human bone marrow derived mesenchymal stem cells cultured under 2D and 3D conditions improves functional recovery in rats after traumatic brain injury. Neurochem. Int. 2017, 111, 69-81. [CrossRef] 